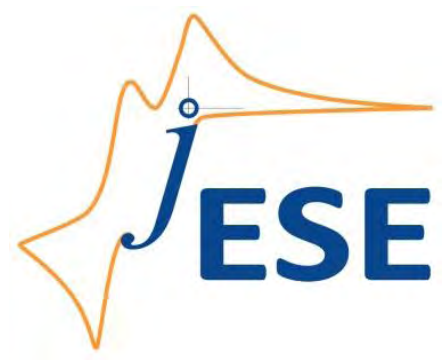

Open Access: ISSN 1847-9286

www.jESE-online.org

Original scientific paper

\title{
Novel electroanalysis of hydroxyurea at glassy carbon and gold electrode surfaces
}

\author{
Keerti M. Naik and Sharanappa T. Nandibewoor ${ }^{\bowtie}$
}

P. G. Department of Studies in Chemistry, Karnatak University, Dharwad 580 003, India

${ }^{\circledR}$ Corresponding author: E-mail: stnandibewoor@yahoo.com, Tel.: +91 836 2770524; Fax: +91 8362747884

Received: July 27, 2014; Revised: September 15, 2014; Published: September 22. 2014

\begin{abstract}
A simple and a novel electroanalysis of hydroxyurea (HU) drug at glassy carbon and gold electrode was investigated for the first time using cyclic, linear sweep and differential pulse voltammetric techniques. The oxidation of $\mathrm{HU}$ was irreversible and exhibited a diffusion controlled process on both electrodes. The oxidation mechanism was proposed. The dependence of the current on $\mathrm{pH}$, the concentration, nature of buffer, and scan rate was investigated to optimize the experimental conditions for the determination of $\mathrm{HU}$. It was found that the optimum buffer $\mathrm{pH}$ was 7.0, a physiological $\mathrm{pH}$. In the range of 0.01 to $1.0 \mathrm{mM}$, the current measured by differential pulse voltammetry showed a linear relationship with $\mathrm{HU}$ concentration with limit of detection of $0.46 \mu \mathrm{M}$ for glassy carbon electrode and $0.92 \mu \mathrm{M}$ for gold electrode. In addition, reproducibility, precision and accuracy of the method were checked as well. The developed method was successfully applied to HU determination in pharmaceutical formulation and human biological fluids. The method finds its applications in quality control laboratories and pharmacokinetics.
\end{abstract}

\section{Keywords}

Hydroxyurea; voltammetry; glassy carbon electrode; gold electrode; electroanalysis; oxidation

\section{Introduction}

Synthesis, chemical analysis and testing of the drugs are important events in pharmaceutical laboratories. The many of the essential drugs has been reported by previous workers, which requires the development and validation of analytical methods for their analysis. The requirements of the quality of the drugs have increased tremendously due to the regulations led by regulatory departments like FDA and ICH. Conventional methods have some shortcomings like time consumption and the use of costly and hazardous chemicals. This in turn motivated the analysts to develop and establish newer and faster methods of analysis of the quality of the drug 
substance and drug products. Hydroxyurea (HU), the simplest, 1-carbon organic antitumor agent, is a member of the substituted urea group and is chemically known as hydroxycarbamide [1]. In 1981 it was reported to have antineoplastic activity against sarcoma [2]. Presently, the primary role of hydroxyurea (Scheme 1) in chemotherapy is the management of granulocytic leukemia and thrombocytosis. It has been used in combination with radiotherapy for carcinomas of the head and neck [3]. HU is used in the treatment of cancer [4], sickle cell anemia [5] and infection with the human immunodeficiency virus (HIV) [6]. HU is a potent, nonalkylating myelosuppressive agent that inhibits DNA synthesis [7].

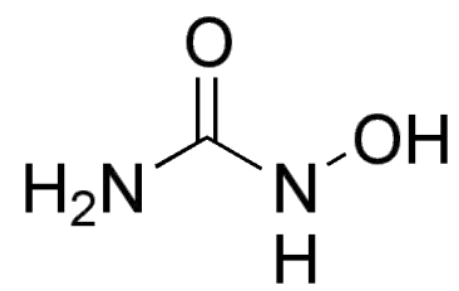

Scheme 1. Structural formula of hydroxyurea.

Only a few analytical procedures have been reported for the determination of HU. Nuclear magnetic resonance spectroscopy [8], liquid chromatographic (LC) procedures have been recommended by the U.S. Pharmacopeia [9] and others [10-12] for determination of hydroxyurea in pharmaceutical formulations and biological fluids. Capillary gas chromatography (GC) with thermionic (N-P) specific detection has also been reported [13]. Main problems encountered in using such methods are either the need for derivatization or the need for time-consuming extraction procedures.

Electrochemical methods may offer certain advantages, such as easier sample preparation, being less time-consuming and offering detection limits and dynamic range comparable to other analytical methods $[14,15]$. These methods have proven useful for the development of very sensitive and selective methods for the determination of organic molecules including drugs. Redox properties of drugs can give insights into their metabolic fate or their in vivo redox processes or pharmaceutical activity [16].

Electrochemical methods, especially differential pulse voltammetry (DPV) make it possible to decrease the analysis time as compared to the time exhaustive chromatographic methods [17]. The advantages of DPV over other electroanalytical techniques are greater speed of analysis, lower consumption of electroactive species in relation to the other electroanalytical techniques, and fewer problems with blocking of the electrode surface.

To the best of our knowledge, there is no report on the electroanalytical method for the determination of HU using glassy carbon (GCE) and gold (GE) electrodes until now. The aim of this study is to establish the suitable experimental conditions, to investigate the voltammetric behavior and oxidation mechanism of HU at GCE and GE by cyclic, linear sweep and differential pulse voltammetric methods for the direct determination of $\mathrm{HU}$ in real samples like pharmaceuticals and human biological fluids.

\section{Experimental}

\section{Reagents and chemicals}

Hydroxyurea (HU) was obtained from Sigma Aldrich and used without further purification. A stock solution of $\mathrm{HU}(1.0 \mathrm{mM})$ was prepared in water and stored in a refrigerator at $4{ }^{\circ} \mathrm{C}$. Standard working solutions were prepared by diluting the stock solution with the selected supporting 
electrolyte. The phosphate buffers from pH 3.0-10.4 were prepared according to the method of Christian and Purdy [18]. The HU containing pharmaceutical product, HYDROX-L, was purchased from a local pharmacy. Other reagents used were of analytical grade. All solutions were prepared with millipore water.

\section{Instrumentation}

Electrochemical measurements were carried on a $\mathrm{CHI} 630 \mathrm{D}$ electrochemical analyzer $(\mathrm{CH}$ Instruments Inc., USA). The voltammetric measurements were obtained in a $10 \mathrm{ml}$ single compartment three-electrode glass cell with $\mathrm{Ag} / \mathrm{AgCl}$ as a reference electrode, a platinum wire as counter electrode and a 2-mm diameter glassy carbon electrode and gold electrode as working electrodes. All the potentials are given against the $\mathrm{Ag} / \mathrm{AgCl}(3 \mathrm{M} \mathrm{KCl}) . \mathrm{pH}$ measurements were performed with Elico LI120 pH meter (Elico Ltd., India). All experiments were carried at an ambient temperature of $25 \pm 0.1^{\circ} \mathrm{C}$.

\section{Analytical procedure}

Polishing of the glassy carbon electrode (GCE) and gold electrode (GE) was done on microcloths (Buehler) glued to flat mirrors. $\mathrm{Al}_{2} \mathrm{O}_{3}(0.3 \mu \mathrm{m})$ was used for polishing before each experiment. Before transferring the electrode to the solution, it was rinsed thoroughly with doubly distilled water. After this mechanical treatment, the GCE and GE were placed in $0.2 \mathrm{M}$ phosphate buffer solution, and various voltammograms were recorded until a steady-state baseline voltammogram was obtained.

The parameters for differential pulse voltammetry (DPV) were initial potential: $0.0 \mathrm{~V}$; final potential: 1.2; increase potential: $0.004 \mathrm{~V}$; amplitude: $0.05 \mathrm{~V}$; frequency: $15 \mathrm{~Hz}$; quiet time: $2 \mathrm{~s}$; sensitivity: $1 \times 10^{-5} \mathrm{~A} / \mathrm{V}$.

\section{Area of the electrodes}

The area of the electrode was obtained by the cyclic voltammetry method using $1.0 \mathrm{mM}$ $\mathrm{K}_{3} \mathrm{Fe}(\mathrm{CN})_{6}$ as a probe at different scan rates. For a reversible process, the following Randles-Sevcik formula can be used [19].

$$
I_{\mathrm{pa}}=0.4463\left(F^{3} / R T\right)^{1 / 2} n^{3 / 2} A D_{0}{ }^{1 / 2} C_{0} U^{1 / 2}
$$

where $I_{\mathrm{pa}}$ refers to the anodic peak current, $n$ is the number of electrons transferred, $A$ is the surface area of the electrode, $D_{0}$ is diffusion coefficient, $v$ is the scan rate, and $C_{0}$ is the concentration of $\mathrm{K}_{3} \mathrm{Fe}(\mathrm{CN})_{6}$. For $1.0 \mathrm{mM} \mathrm{K}_{3} \mathrm{Fe}(\mathrm{CN})_{6}$ in $0.1 \mathrm{M} \mathrm{KCl}$ electrolyte, $T=298 \mathrm{~K}, R=8.314 \mathrm{~J} \mathrm{~K}^{-1} \mathrm{~mol}^{-1}$, $F=96480 \mathrm{C} \mathrm{mol}^{-1}, n=1, D_{0}=7.6 \times 10^{-6} \mathrm{~cm}^{2} \mathrm{~s}^{-1}$, then from the slope of the plot of $I_{\mathrm{pa}} v \mathrm{~s} . U^{1 / 2}$ relation, the electroactive area was calculated. In our experiment the slope was $2.46 \times 10^{-6} \mu \mathrm{A}\left(\mathrm{V} \mathrm{s}^{-1}\right)^{-1 / 2}$ and $2 \times 10^{-5} \mu \mathrm{A}\left(\mathrm{V} \mathrm{s}^{-1}\right)^{-1 / 2}$ and the area of electrodes were calculated to be $0.033 \mathrm{~cm}^{2}$ and $0.0269 \mathrm{~cm}^{2}$ for GCE and GE.

\section{Sample preparation}

Two pieces of HU containing tablets were weighed and ground to a homogeneous fine powder in a mortar. A portion equivalent to a stock solution of a concentration of about $1.0 \mathrm{mM}$ was accurately weighed and dissolved in water. The contents were sonicated for 20 min to affect complete dissolution. The excipient was separated by filtration and the residue was washed three times with water. The filtrate was diluted to $1.0 \mathrm{mM}$. Appropriate solutions were prepared by taking suitable aliquots from this stock solution and diluting them with the phosphate buffer solutions. Each solution was transferred to the voltammetric cell. The differential pulse 
voltammograms were subsequently recorded following the optimized conditions. The content of the drug in tablet was determined referring to the calibration graph or regression analysis. To study the accuracy of the proposed method and to check the interferences from excipients used in the dosage form, recovery experiments were carried out. The concentration of HU was calculated using standard addition method.

\section{Plasma sample preparation}

Human blood samples were collected in dry and evacuated tubes (which contained saline and sodium citrate solution) from a healthy volunteer. The samples were handled at room temperature and were centrifuged for $10 \mathrm{~min}$ at $1500 \mathrm{rpm}$ for the separation of plasma within $1 \mathrm{~h}$ of collection. The samples were then transferred to polypropylene tubes and stored at $20{ }^{\circ} \mathrm{C}$ until analysis. The plasma samples, $0.2 \mathrm{~mL}$, were deproteinized with $2 \mathrm{~mL}$ of methanol. After vortexing for $15 \mathrm{~min}$, the mixture was then centrifuged for $15 \mathrm{~min}$ at $6000 \mathrm{rpm}$, and supernatants were collected. The supernatants were spiked with known amounts of HU. Appropriate volumes of this solution were added to phosphate buffer as supporting electrolyte and the voltammograms were then recorded.

\section{Results and discussion}

\section{Cyclic voltammetric behavior of hydroxyurea}

The electrochemical behavior of HU at GCE and GE were studied using cyclic voltammetry (CV) at physiological $\mathrm{pH}=7.0$. The cyclic voltammograms obtained for $1.0 \mathrm{mM}$ HU solution at a scan rate of $50 \mathrm{mV} \mathrm{s}^{-1}$ exhibit well-defined irreversible anodic peaks at $0.59,0.78$ and $0.91 \mathrm{~V}$ at glassy carbon electrode and $0.32,0.84$ and $1.13 \mathrm{~V}$ at gold electrode. The cathodic peak was appeared at $0.59 \mathrm{~V}$ corresponding to reduction of gold oxides [20]. The results are shown in Figure 1. However, no peak was observed in the reverse scan, suggesting that the oxidation process is an irreversible one. There are two possibilities, either the charge transfer kinetics are slow at surfaces of GCE and GE or products of the electron transfer were unstable and the reaction is accompanied by the fast chemical follow-up reaction resulting in electrochemically inactive products.

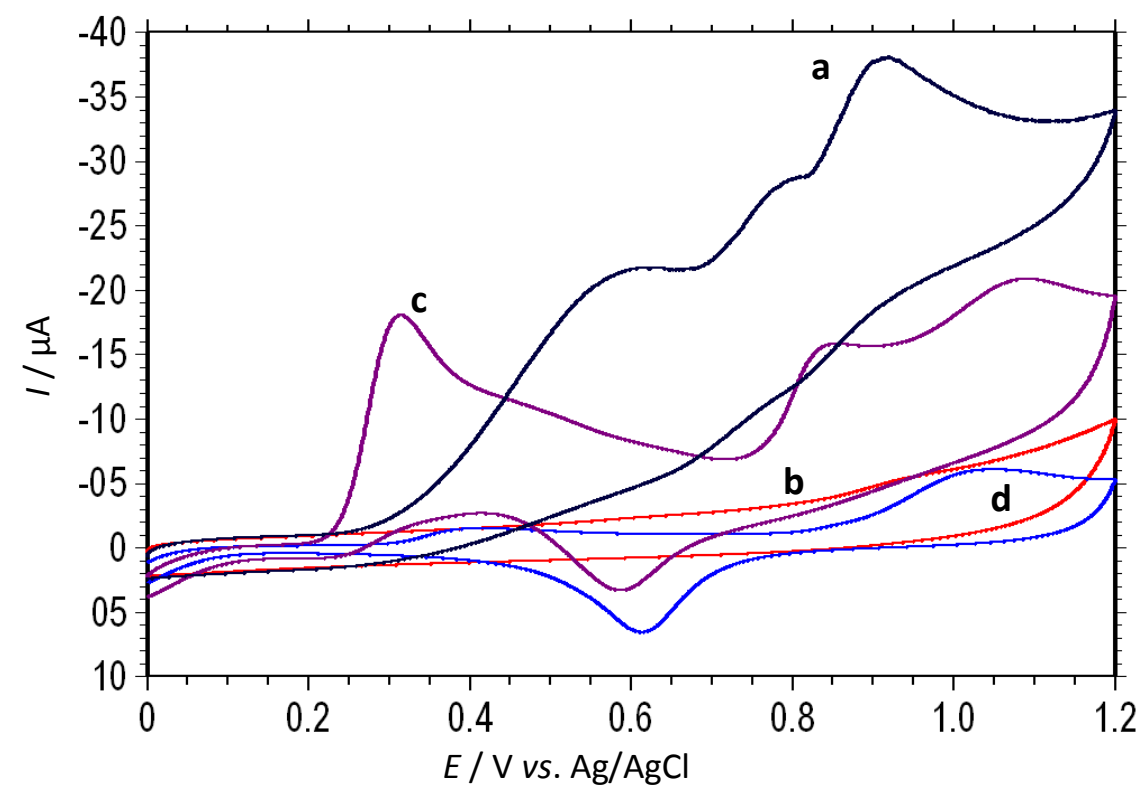

Figure 1. Cyclic voltammograms obtained for $1.0 \mathrm{mM} \mathrm{HU}$ on glassy carbon electrode (GCE) and gold electrode (GE): (a) HU on GCE, (b) blank run of GCE, (c) HU on GE and (d) blank run of GE in $p H$ 7.0, $0.2 \mathrm{M}$ buffer at $\mathrm{V}=50 \mathrm{mV} \mathrm{s}^{-1}$. 


\section{Influence of $\mathrm{pH}$}

The electrode reaction might be affected by $\mathrm{pH}$ of the medium. The electrooxidation of $1.0 \mathrm{mM} \mathrm{HU}$ was studied over the $\mathrm{pH}$ range of 3.0 - 10.4 in phosphate buffer solution by cyclic voltammetry. A well-defined sharp oxidation peaks were appeared only in the $\mathrm{pH}$ range 7.0 - 10.4 (Figures $2 \mathrm{~A}$ and $2 \mathrm{~B}$ ). Below the $\mathrm{pH} 7.0$, the oxidation peak was not observed; hence the $\mathrm{pH}$ study was restricted only in the range from 7.0 to 10.4 . However, with the increase in the $\mathrm{pH}$ of the solution, the oxidation peak current decreased continuously from 7.0 - 10.4. A stability study showed that the $\mathrm{HU}$ was unstable in aqueous solutions even at $4{ }^{\circ} \mathrm{C}$ [13] since it degrades with the production of hydroxylamine. The peak potential $\left(E_{\mathrm{p}}\right)$ shifted towards less positive potentials with an increase in $\mathrm{pH}$, suggesting the involvement of protons in the chemical process. From the plot of $I_{\text {pa }} \mathrm{Vs} \mathrm{pH}$ of GCE and GE it is clear that the peak height decreased with $\mathrm{pH}$. Since the best sensitivity was achieved at $\mathrm{pH} 7.0$, this $\mathrm{pH}$ was selected for further experiments.

A

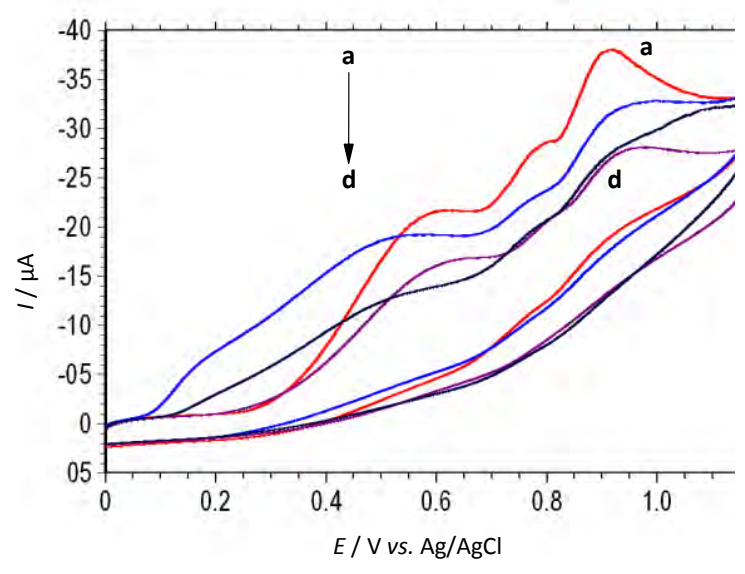

B

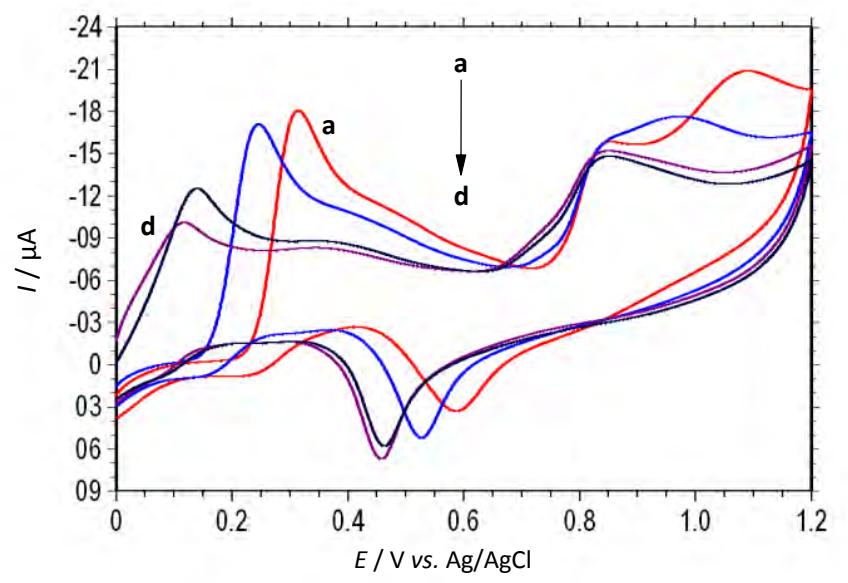

Figure 2. Influence of $\mathrm{pH}$ on the shape of the peak in phosphate buffer solution at (a) 7.0, (b) 8.0, (c) 9.2 and (d) pH 10.4. For 1.0 mM HU on A - GCE, B - GE.

\section{Influence of scan rate}

Useful information involving electrochemical mechanism can be acquired from the relationship between peak current and scan rate. Therefore, the voltammetric behavior of $\mathrm{HU}$ at different scan rates from 10 to $50 \mathrm{mV} \mathrm{s}^{-1}$ was also studied using linear sweep voltammetry (Figures 3A and 3B). Scan rate studies were carried out to assess whether the processes on GCE and GE were under diffusion or adsorption-controlled.

The plot of square root of scan rate with the peak current showed a linear relationship in the range of 10 to $50 \mathrm{mV} \mathrm{s}^{-1}$ which is of diffusion controlled process [21].

A plot of logarithm of anodic peak current vs. logarithm of scan rate gave a straight line with a slope of 0.424 and 0.516 (Figure $3 C$ ), which are close to the theoretical value of 0.5 for a purely diffusion-controlled process [22] which in turn confirms that the processes are diffusion controlled.

The $E_{\mathrm{p}}$ of the oxidation peak was also dependent on scan rate. The peak potential shifted to more positive values on increasing the scan rate, which confirms the irreversibility of the oxidation process, and a linear relationship between peak potential and logarithm of scan rate (Figure 3D).

For an irreversible electrode process, according to Laviron [23] $E_{\mathrm{p}}$ is defined by the following equation:

$$
E_{\mathrm{p}}=E^{o^{\prime}}+\frac{2.303 R T}{\alpha n F} \log \frac{R T k^{\circ}}{\alpha n F}+\frac{2.303 R T}{\alpha n F} \log v
$$


A

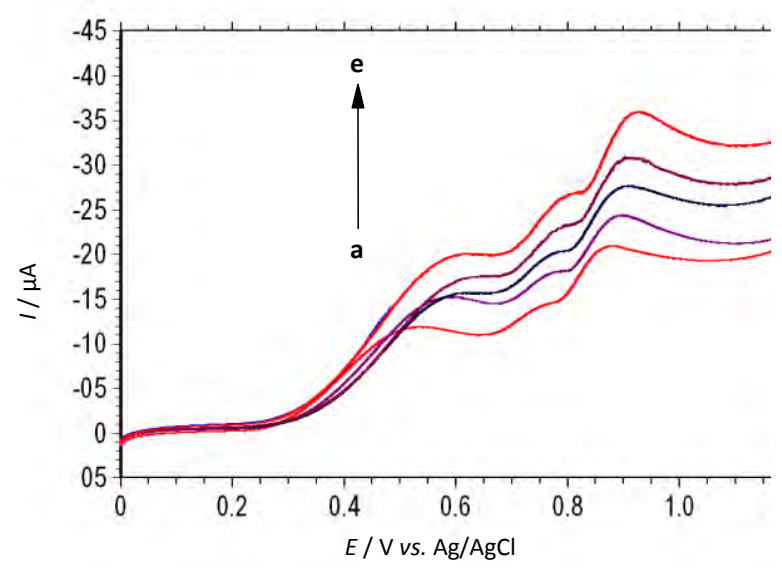

C

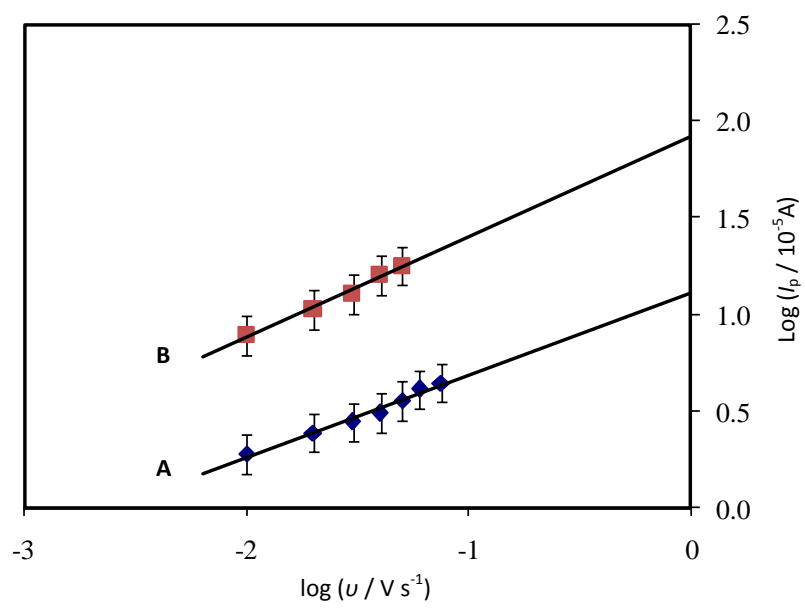

B

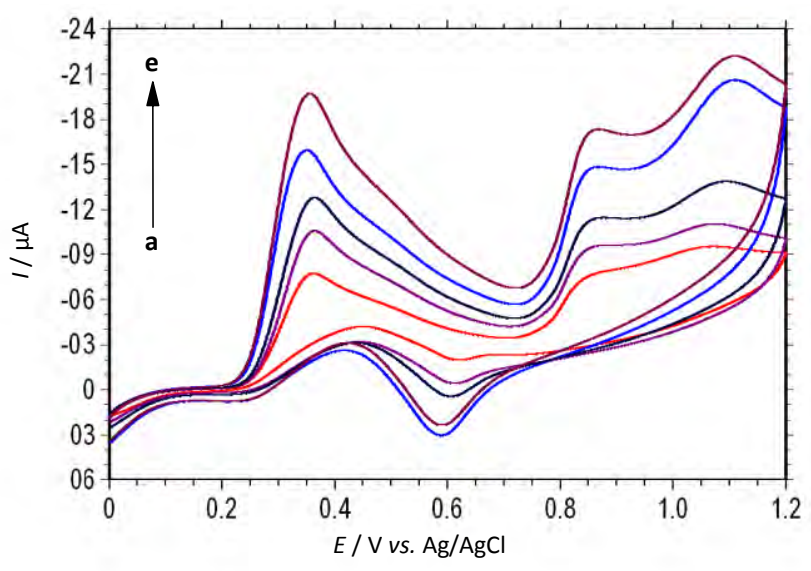

D

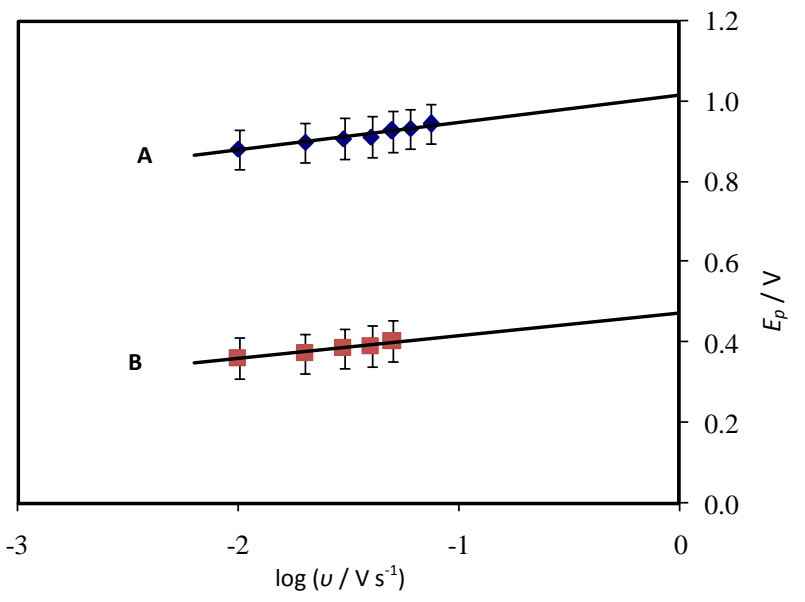

Figure 3. Linear sweep voltammograms of $1.0 \mathrm{mM} \mathrm{HU}$ on

$\boldsymbol{A}-G C E$ and $\boldsymbol{B}-G E$, with different scan rates, $\boldsymbol{a}$ - $\boldsymbol{e}$ were $10,20,30,40$ and $50 \mathrm{mV} \mathrm{s}^{-1}$, respectively; $C$-Dependence of the logarithm of peak current $\mathrm{I}_{p} / 10^{-5} \mathrm{~A}$ on log of scan rate $\left(\mathrm{U} / \mathrm{V} \mathrm{s} \mathrm{s}^{-1}\right) ; 1.0 \mathrm{mM} \mathrm{HU}$ on (A) GCE $\left(\log \left(I_{p} / \mu A\right)=0.424 \log \left(u / V s^{-1}\right)+1.110 ; r=0.9810\right)$ and

(B) $G E\left(\log \left(\mathrm{I}_{p} / \mu A\right)=0.516 \log \left(\mathrm{u} / V s^{-1}\right)+1.914 ; \mathrm{r}=0.9890\right)$;

$D$ - Relationship between peak potential $\mathrm{E}_{p} / \mathrm{V}$ and logarithm of scan rate $\log \left(\mathrm{U} / \mathrm{V} \mathrm{s} \mathrm{s}^{-1}\right) ; 1.0 \mathrm{mM} \mathrm{HU}$ on (A) $G C E\left(E_{p} / V=0.059 \log \left(u / V s^{-1}\right)+0.998 ; r=0.9860\right)$ and (B) $G E\left(E_{p} / V=0.057 \log \left(u / V s^{-1}\right)+0.474 ; r=0.9720\right)$.

where $\alpha$ is the transfer coefficient, $k^{\circ}$ is the standard heterogeneous rate constant of the reaction, $n$ is the number of electrons transferred, $v$ is the scan rate, and $E^{\circ}$ is the formal redox potential. Other symbols have their usual meanings. Thus, the value of $\alpha$ can be easily calculated from the slope of $E_{\mathrm{p}} v$ s. $\log U$. In this system, the slope is 0.059 and 0.057 for GCE and GE, taking $T=298 \mathrm{~K}$ and substituting the values of $R$ and $F$, an was calculated. According to Bard and Faulkner [24] $\alpha$ can be given as

$$
\alpha / \mathrm{mV}=\frac{47.7}{E_{\mathrm{p}}-E_{\mathrm{p} / 2}}
$$

where $E_{\mathrm{p} / 2}$ is the potential where the current is at half the peak value. So, from this we obtained the value of $\alpha$. Further, the number of electrons $(n)$ transferred in the electrooxidation of HU was also calculated using linear sweep voltammetry. The value of $k^{\circ}$ can be determined from the intercept of the above plot if the value of $E^{\mathrm{o}^{\prime}}$ is known. The value of $E^{\mathrm{o}^{\prime}}$ in Equation (2) can be obtained 
from the intercept of $E_{\mathrm{p}}$ versus $u$ curve by extrapolating to the vertical axis at $u=0$ [24]. All the values of $\alpha n, \alpha, n, E^{\mathrm{o}^{\prime}}$ and $k^{\circ}$ obtained from linear sweep voltammetry are tabulated in Table 1.

Table 1. The calculated values of $\alpha \mathrm{n}, \alpha, n, \mathrm{E}^{\mathrm{o}^{\prime}}$ and $\mathrm{k}^{\circ}$ for the electro-oxidation of $\mathrm{HU}$ by linear sweep voltammetry (LSV) at GCE and GE

\begin{tabular}{ccc}
\hline Parameters & \multicolumn{2}{c}{ Linear sweep voltammetry } \\
\hline$\alpha n$ & Glassy carbon electrode & Gold electrode \\
\hline$\alpha$ & 1.0024 & 1.0375 \\
\hline$n$ & 0.5690 & 0.5860 \\
\hline$E^{\mathrm{o}^{\prime}} / \mathrm{V}$ & 1.76 & 1.78 \\
\hline$k^{\circ} / \mathrm{min}^{-1}$ & 0.8740 & 0.3520 \\
\hline
\end{tabular}

\section{Calibration curve and detection limit}

To develop a rapid and sensitive voltammetric method for the determination of $\mathrm{HU}$, differential pulse voltammetric method was adopted as the peaks obtained are better defined at lower concentration of $\mathrm{HU}$ than those obtained by cyclic voltammetry. According to the obtained results, it was possible to apply this technique to the quantitative determination of HU. The phosphate buffer solution of $\mathrm{pH}=7.0$ was selected as the supporting electrolyte for the quantification of $\mathrm{HU}$ as it gave a maximum peak current at $\mathrm{pH}=7.0$ for both GCE and GE. Differential pulse voltammograms obtained with increasing amounts of HU showed that the peak current increased with increasing concentration, as shown in Figures $4 \mathrm{~A}$ and 4B. The concentration of $\mathrm{HU}$ was varied from 0.01 to $1.0 \mathrm{mM}$. Figure $4 \mathrm{C}$ shows that the graph of anodic peak current vs. concentration of $\mathrm{HU}$ shows two linear relationships in the range 0.01 to 0.08 and 0.2 to $1.0 \mathrm{mM}$.

Above $1.0 \mathrm{mM}$, deviation from linearity was obtained which might be due to the adsorption of $\mathrm{HU}$ or its oxidation products on the electrode surface. The decrease of sensitivity (slope) in the second linear range is likely to the kinetic limitations [25]. Related statistical data of the calibration curves were obtained from the six different determinations. The detection limits (LOD) and quantification (LOQ) in the lower range regions were given in Table 2.

Table 2. The Values of LOD and LOQ for HU at GCE and GE by using differential pulse voltammetric method

Glassy carbon electrode (GCE)

\begin{tabular}{ccc}
\hline Linearity range, $\mathrm{mM}$ & 0.01 to 1.0 & 0.01 to 1.0 \\
\hline Number of data points & 06 & 06 \\
\hline Limit of detection (LOD), $\mu \mathrm{M}$ & 0.46 & 0.92 \\
\hline Limit of quantification (LOQ), $\mu \mathrm{M}$ & 1.54 & 3.08 \\
\hline Repeatability - RSD, \% & 1.14 & 2.02 \\
\hline Reproducibility - RSD, \% & 1.46 & 2.48 \\
\hline
\end{tabular}

During the actual analysis, the analytical response was checked through the peak potential and its height. No change in peak potential was observed within an hour, while its height changed about $\pm 1 \%$ for five different quantitative determinations. This proposed method was better as compared with other reported methods $[11,26]$. 
To ascertain the repeatability of the analysis, six measurements of $1.0 \mathrm{mM}$ HU solution were carried out using GCE and GE at intervals of $30 \mathrm{~min}$. The RSD value of peak current was found to be $1.14 \%$ and $2.02 \%$ respectively, which indicated that the methods had good repeatability. As to the reproducibility between days, it was similar to that of within day repeatability if the temperature was kept almost unchanged.

A

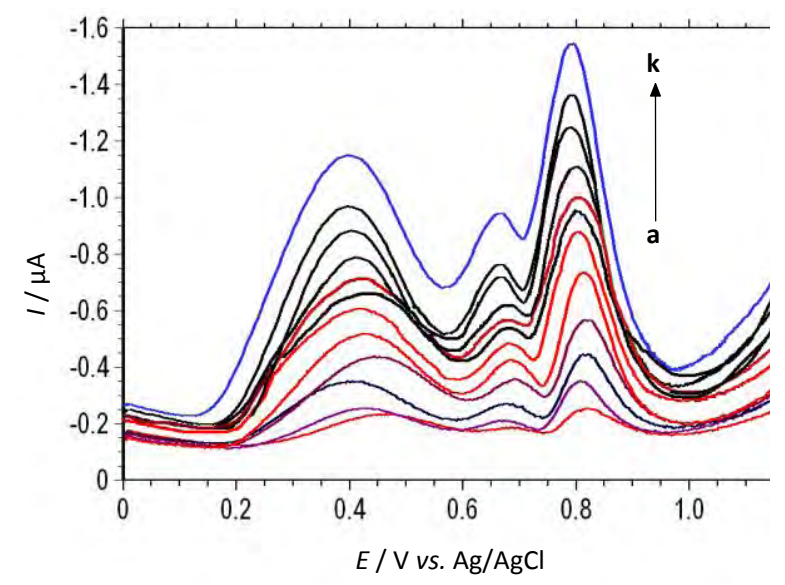

B

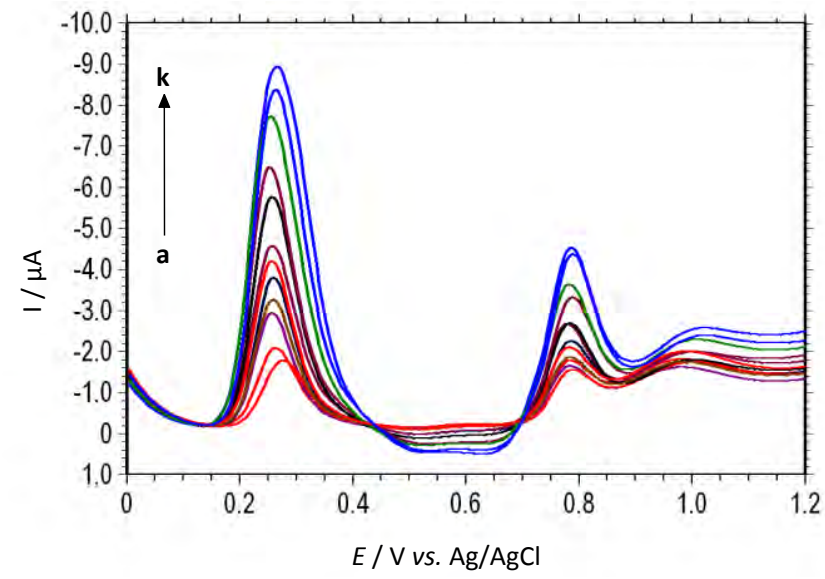

C

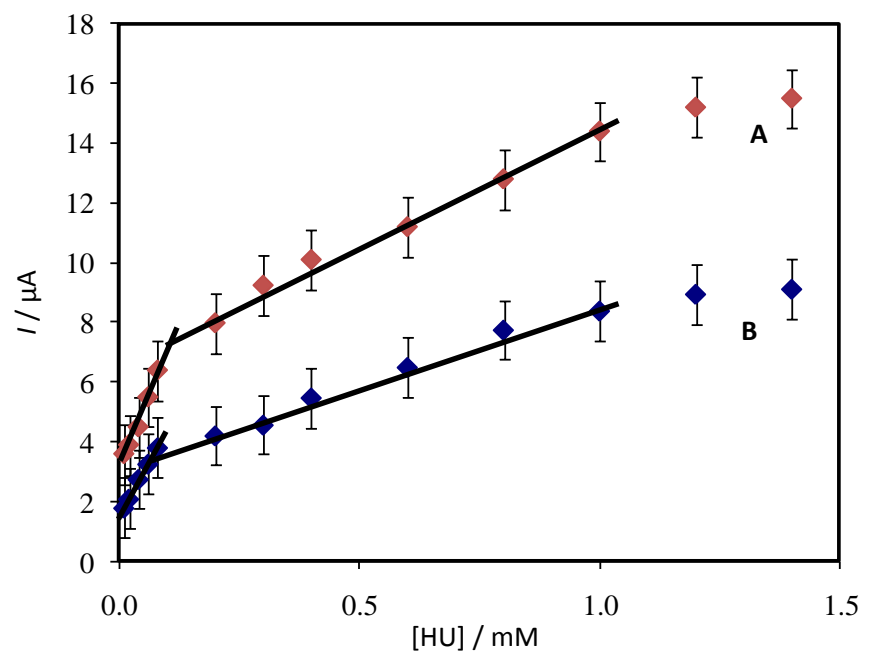

Figure 4. Differential pulse voltammograms of $\boldsymbol{A}-G C E$ and $\boldsymbol{B}-G E$ in $H U$ solution at different concentrations: (a) 0.01, (b) 0.02, (c) 0.04, (d) 0.06, (e) 0.08, (f) 0.2 (g) 0.3, (h) 0.4, (i) 0.6, (j) 0.8 and (k) $1.0 \mathrm{mM}$ C - Plot of peak current I/ $\mu$ A against the concentration of $\mathrm{HU}[\mathrm{HU}] / \mathrm{mM}$

(A) $G C E\left(\mathrm{I}_{p} / \mu A=40.30 \mathrm{C} / \mathrm{mM}+3.0870 ; \mathrm{r}=0.9880 ; \mathrm{I}_{p} / \mu A=7.625 \mathrm{C} / \mathrm{mM}+6.7590 ; r=0.9910\right)$ and

(B) $G E\left(\mathrm{l}_{p} / \mu A=28.87 \mathrm{C} / \mathrm{mM}+1.5370 ; r=0.9970 ; \mathrm{l}_{p} / \mu A=5.473 \mathrm{C} / \mathrm{mM}+3.1490 ; r=0.9870\right)$.

\section{Effect of excipients}

For the possible analytical application of the proposed method, the effect of some common excipients used in pharmaceutical preparations was examined. The tolerance limit was defined as the maximum concentration of the interfering substance that caused an error less than $\pm 5 \%$ for determination of HU. Under the optimum experimental conditions, the effects of potential excipients on the voltammetric response of $1.0 \mathrm{mM} \mathrm{HU}$ as a standard were evaluated. The experimental results showed that hundred-fold excess of citric acid, dextrose, glucose, gum acacia, lactose, starch, and sucrose did not interfere with the voltammetric signal of HU. Thus, the procedures were able to assay $\mathrm{HU}$ in the presence of excipients, and hence it can be considered specific. 


\section{Determination of HU in pharmaceutical preparations and recovery test}

The proposed method was validated for the determination of $\mathrm{HU}$ in pharmaceutical preparations in tablets as a real sample by applying DPV using the standard addition method. The procedure for the tablet analysis was followed as described in sample preparation section. The results are in good agreement with the content marked in the label (Table 3). Recovery studies were carried out after the addition of known amounts of the drug to various pre-analyzed formulations of HU. The recovery in the sample was found to be $98.83 \%$ with RSD of $1.37 \%$.

Table 3. Determination of HU in pharmaceutical formulation samples using differential pulse voltammetric method

\begin{tabular}{ccccc} 
& \multicolumn{2}{c}{ Labeled claim 500.0, mg } & \multicolumn{2}{c}{ Added 20.0 mg } \\
\cline { 2 - 5 } & GCE & GE & GCE & GE \\
\hline Amount found, $\mathrm{mg}^{\mathrm{a}}$ & 499.2 & 492.5 & 19.5 & 19.2 \\
\hline Recovery, \% & 98.83 & 98.50 & 97.78 & 96.11 \\
\hline RSD, \% & 1.37 & 1.87 & 3.51 & 3.54 \\
\hline Bias, \% & -1.16 & -1.50 & -2.22 & -3.88 \\
\hline
\end{tabular}

${ }^{\mathrm{a}}$ average of six determinations.

\section{Detection of HU in spiked human plasma samples}

The applicability of the DPV to the determination of HU in spiked human plasma sample was investigated. The recoveries from human plasma were measured by spiking drug free plasma with known amounts of $\mathrm{HU}$. The plasma samples were prepared as described in plasma sample preparation section. A quantitative analysis can be carried out by adding the standard solution of $\mathrm{HU}$ into the detect system of plasma sample. The calibration graph was used for the determination of spiked HU in plasma samples. The detection results obtained for four plasma samples are listed in Table 4.

Table 4. Determination of HU in spiked human plasma samples using differential pulse voltammetric method

\begin{tabular}{ccccccccccc}
\hline $\begin{array}{c}\text { Human } \\
\text { plasma } \\
\text { sample }\end{array}$ & $\begin{array}{c}\text { Amount of } \\
\text { spiked HU, } \\
\mathbf{1 0 - 4} \mathbf{M}\end{array}$ & \multicolumn{2}{c}{$\begin{array}{c}\text { Amount of detected HU*, } \\
\mathbf{1 0 - 4} \mathbf{M}\end{array}$} & GCE & Gecovery, $\%$ & \multicolumn{2}{c}{ RSD, $\%$} & \multicolumn{2}{c}{ Bias, \% } \\
\hline 1 & 0.3 & 0.3002 & 0.2998 & 100.1 & 99.95 & 2.92 & 3.12 & 0.067 & -0.067 \\
\hline 2 & 0.7 & 0.6863 & 0.6797 & 98.05 & 97.10 & 2.67 & 2.25 & -1.96 & -2.90 \\
\hline 3 & 3.0 & 3.0407 & 3.0074 & 101.4 & 100.2 & 2.37 & 0.48 & 1.36 & 0.25 \\
\hline 4 & 7.0 & 6.9620 & 6.9820 & 99.45 & 99.74 & 1.79 & 0.96 & -0.54 & -0.26 \\
\hline
\end{tabular}

* average of six determinations

\section{Detection of $\mathrm{HU}$ in urine samples}

The developed differential pulse voltammetric method was also applied for the determination of $\mathrm{HU}$ in spiked urine samples. The recoveries from urine were measured by spiking drug-free urine with known amounts of HU. The urine samples were diluted 100 times with the phosphate buffer solution before analysis without further pretreatments. A quantitative determination can be carried out by adding the standard solution of $\mathrm{HU}$ into the detect system of urine sample. The calibration graph was used for the determination of spiked $\mathrm{HU}$ in urine samples. The detection results of four urine samples obtained are listed in Table 5. Thus, satisfactory recoveries of the 
analyte from the real samples and a good agreement between the concentration ranges studied and the real ranges encountered in the urine samples when treated with the drug make the developed method applicable in clinical analysis.

Table 5. Determination of $H U$ in urine samples using differential pulse voltammetric method

\begin{tabular}{|c|c|c|c|c|c|c|c|c|c|}
\hline \multirow{2}{*}{$\begin{array}{l}\text { Urine } \\
\text { sample }\end{array}$} & \multirow{2}{*}{$\begin{array}{c}\text { Amount of } \\
\text { spiked } \mathrm{HU} \text {, } \\
10^{-4} \mathrm{M}\end{array}$} & \multicolumn{2}{|c|}{$\begin{array}{c}\text { Amount of detected HU*, } \\
10^{-4} \mathrm{M}\end{array}$} & \multicolumn{2}{|c|}{ Recovery, \% } & \multicolumn{2}{|c|}{ RSD, \% } & \multicolumn{2}{|c|}{ Bias, \% } \\
\hline & & GCE & GE & GCE & GE & GCE & GE & GCE & GE \\
\hline 1 & 0.3 & 0.3025 & 0.3092 & 100.8 & 103.1 & 2.32 & 4.12 & 0.83 & 3.07 \\
\hline 2 & 0.7 & 0.6995 & 0.7101 & 99.94 & 101.4 & 0.34 & 1.41 & -0.07 & 1.44 \\
\hline 3 & 3.0 & 2.9424 & 2.9424 & 98.08 & 98.08 & 1.73 & 1.73 & -1.92 & -1.92 \\
\hline 4 & 7.0 & 7.0799 & 6.9966 & 101.1 & 99.95 & 1.35 & 0.82 & 1.14 & -0.05 \\
\hline
\end{tabular}

* average of six determinations.

\section{Conclusions}

The voltammetric oxidation of $\mathrm{HU}$ at glassy carbon and gold electrodes under physiological condition, i.e., $\mathrm{pH} 7.0$ in phosphate buffer solutions has been investigated. HU undergoes two electron-two proton change and follows the diffusion-controlled process at both the electrodes. A suitable oxidation mechanism was proposed. The proposed method can be used successfully to assay the drug in pharmaceutical dosage form as well as in spiked real samples. High percentage recovery and study of excipients showed that the method is free from the interferences of the commonly used excipients in the formulations of drugs. The proposed method is suitable for quality control laboratories as well as pharmacokinetic studies where economy and time are essential.

Acknowledgment: Keerti M. Naik thanks UGC, New Delhi for the award of Research Fellowship in Science for Meritorious Students (RFSMS).

\section{Nomenclature}

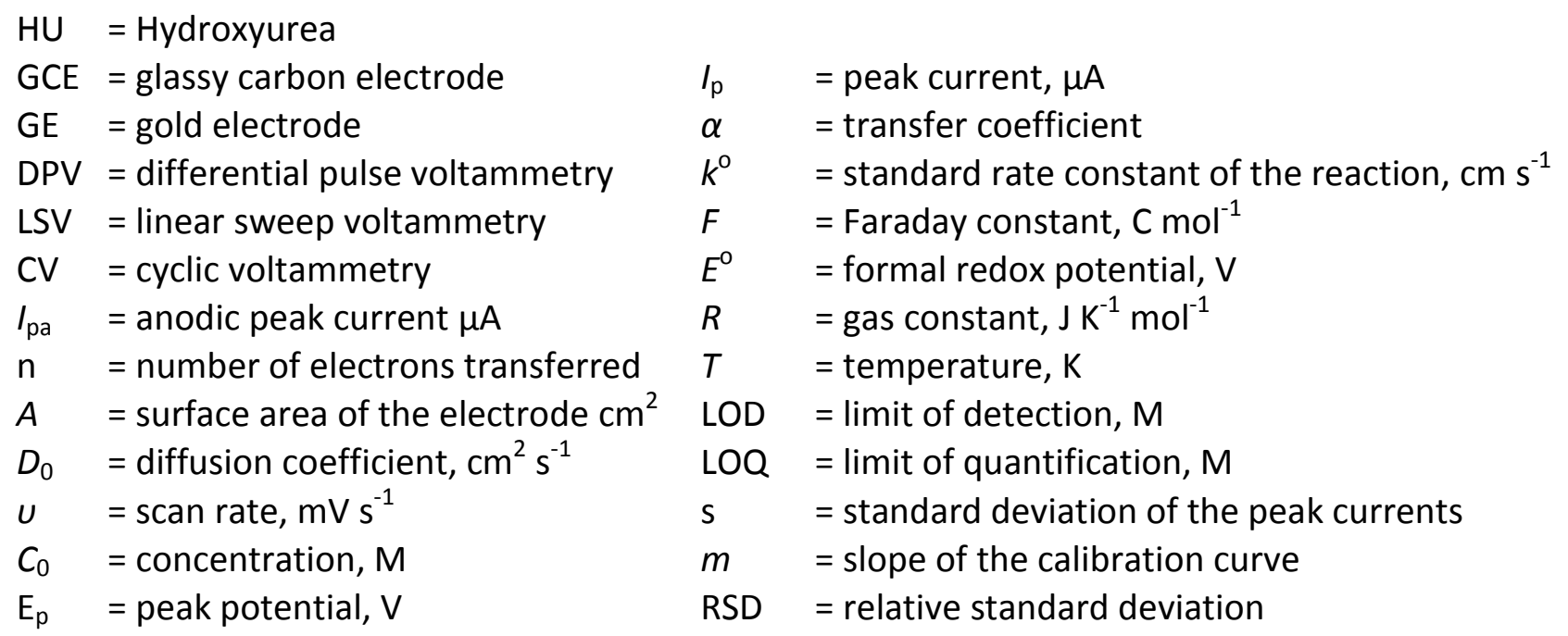

\section{References}

[1] R. Donehower, In Cancer Chemotherapy: Principles and Practice, B. A. Chabner, J. M. Collins, (Eds), J. B. Lippincott Co., Philadelphia, PA, 1990.

[2] S. J. P. Van Belle, M. M. de Planque, I. E. Smith, A. T. van Oosterom, T. J. Schoemaker, W. Deneve, J. G. McVie, Cancer Chemother. Pharmacol. 18 (1986) 27-32. 
[3] D. Heerenberg, Basic Principles in Therapeutics, McGraw-Hill, New York, 1992.

[4] R. C. Donehower, Semin. Oncol. 19 (1992) 11-19.

[5] S. Charache, G. J. Dover, R. D. Moore, Blood 79 (1992) 2555-2565.

[6] W. Y. Gao, A. Cara, R. C. Gallo, F. Lori, Proc. Natl. Acad. Sci. U.S.A. 90 (1993), 8925-8928.

[7] I. H. Krakoff, N. C. Brown, P. Reichard, Cancer Res. 28 (1968) 1559-1565.

[8] K. B. Main, T. Medwick, L. C. Bailey, J. H. Shinkai, Pharm. Res. 4 (1987) 412-415.

[9] The U. S. Pharmacopia $23^{\text {rd }}$ Ed., U. S. Pharmacopeial Convention, Rockville, MD, 1995.

[10] Q. Wang, H. J. Altermatt, H. B. Ris, B.E. Reynolds, J. C. M. Stewart, R. Bonnett, C. K. Lim, Biomed. Chromatogr. 7 (1993) 155-157.

[11] E. W. Iyamu, P. D. Roa, P. Koposmbut, M. D. P. Aguinaga, E.A . Turner, J. Chromatogr. B Biomed. Appl. 709 (1998) 119-126.

[12] K. K. Manouilov, T. R. McGruire, P. R. Gwilt, J. Chromatogr. B Biomed. Appl. 708 (1998) 321324.

[13] A. El-Yazigi, S. Al-Rawithi, Pharm. Res. 9 (1992) 115-118.

[14] C. Radovan, D. Cinghita, F. Manea, M. Mincea, C. Cofan, V. Ostafe, Sensors 8 (2008) 43304349.

[15] C. D. Souza, O. C. Braga, I. C. Vieira, A. Spinelli, Sens. Actuators B: Chem. 135 (2008) 66-73.

[16] S. A. Ozkan, B. Uslu, H. Y. Aboul-Enein, Crit. Rev. Anal. Chem. 33 (2003) 155-181.

[17] N. Erk, Anal. Bioanal. Chem. 378 (2004) 1351-1356.

[18] G. D. Christian, W. C. Purdy, J. Electroanal. Chem. 3 (1962) 363-367.

[19] B. Rezaei, S. Damiri, Sens. Actuators B 134 (2008) 324-331.

[20] C. Barus, P. Gros, M. Comtat, S. Daunes-marion, R. Tarroux, Electrochim. Acta 52 (2007) 7978-7985.

[21] K. M. Naik, S. T. Nandibewor, Sensors and Actuators A 212 (2014) 127-132

[22] D. K. Gosser, Cyclic Voltammetry: Simulation and Analysis of Reaction Mechanisms; VCH: New York, 1993.

[23] E. Laviron, J. Electroanal. Chem. 101 (1979) 19-29.

[24] A. J. Bard, L. R. Faulkner, Electrochemical methods; Fundamentals and Applications. $2^{\text {nd }}$ edn, Wiley, 2004.

[25] M. Mazloum-Ardakani, H. Rajabi, H. Beitollahi, B. B. F. Mirjalili, A. Akbari, N. Taghavinia, Int. J. Electrochem. Sci. 5 (2010) 147-157.

[26] J. Havard, J. Grygiel, D. Sampson, J. Chromatogr. B. 584 (1992) 270-274.

(C) 2014 by the authors; licensee IAPC, Zagreb, Croatia. This article is an open-access article distributed under the terms and conditions of the Creative Commons Attribution license (http://creativecommons.org/licenses/by/3.0/) (cc) EY 